\title{
In vitro biosynthesis of acetan using electroporated Acetobacter xylinum cells as enzyme preparations
}

\author{
Carlos E. Semino and Marcelo A. Dankert*
}

\begin{abstract}
Instituto de Investigaciones Bioquimicas 'Fundación Campomar', Facultad de Ciencias Exactas y Naturales and Consejo Nacional de Investigaciones Cientificas y Técnicas. Av. Patricias Argentinas 435, (1405) Buenos Aires, Argentina
\end{abstract}

(Received 22 February 1993; revised 20 May 1993; accepted 26 May 1993)

\begin{abstract}
Acetobacter xylinum strain NRRL B42 and its derivative RCGr1 produce a complex exopolysaccharide, acetan, containing glucose, mannose, glucuronic acid and rhamnose in a 4:1:1:1 molar ratio. The in vitro synthesis of acetan, employing electroporated cells as the enzyme system and the respective ${ }^{14} \mathrm{C}$-labelled sugar nucleotide precursors, is described. The synthesis of the prenyl-linked heptasaccharide repeat unit, already observed in EDTA-treated cells, was confirmed, as well as the formation of other saccharides not related to acetan biosynthesis, including a high molecular mass glucan. The acetan formed was characterized by gel filtration, specific radioactive labelling with each precursor and permethylation analysis. It was also shown that acetan contains acetyl residues and that using $\left[{ }^{14} \mathrm{C}\right]$ acetyl $\mathrm{CoA}$ as donor, radioactivity was detected both at the polysaccharide and at the prenyl-linked oligosaccharide stage.
\end{abstract}

\section{Introduction}

Acetobacter xylinum is a Gram-negative bacterium characterized by its capacity to synthesize cellulose. Work from this laboratory has shown that, in addition, some strains of this organism are also able to produce a complex exopolysaccharide, acetan, that contains glucose (Glc), mannose (Man), glucuronic acid (GlcA) and rhamnose (Rha) in a 4:1:1:1 molar ratio (Couso et al., 1987; Jansson et al., 1993). The proposed structure can be considered a substituted cellulose, of the type assigned to xanthan (Jansson et al., 1975), in which pentasaccharide side chains are linked to alternate glucoses of the $\beta$ - $(1 \rightarrow 4)$-glucose main chain (Fig. 1$)$.

The synthesis of the lipid diphosphate-linked heptasaccharide repeat unit of acetan in vitro has already been described, using EDTA-treated cells as enzyme system and UDP-Glc, GDP-Man, UDP-GlcA and TDP-Rha as sequential sugar donors (Couso et al., 1982). Furthermore, using different Acetobacter xylinum strains, a correlation was found between the capacity to ac-

*Author for correspondence. Tel. +541884015; fax +541865 2246; e-mail iibcom\%iibf.edu.ar@cunyvm.cuny.edu or iibcom\%iibf.edu.ar@uunet.uu.net.

Abbreviations: Glc, glucose; GlcA, glucuronic acid; Man, mannose; Rha, rhamnose. cumulate lipid-linked heptasaccharide in vitro and the production of acetan in vivo, suggesting a precursorproduct relationship (Iñon de Iannino et al., 1988). Nevertheless the in vitro synthesis of acetan could not be demonstrated with the enzyme preparations employed. A similar situation has been observed with Rhizobium meliloti (Tolmasky et al., 1982), Agrobacterium tumefaciens (Staneloni et al., 1984) and Rhizobium trifolii (Bossio et al., 1986) preparations. In all these systems the synthesis of the respective repeat units was obtained in vitro but the formation of the polysaccharide, i.e. the presumed polymerization process, could not be detected.

This is not the case for xanthan biosynthesis, an exopolysaccharide produced by Xanthomonas campestris that contains glucose, mannose and glucuronic acid in a 2:2:1 molar ratio, and acetate and pyruvate substituents (Jansson et al., 1975). It was possible to demonstrate, using EDTA-treated cells and the appropriate sugar nucleotide donors, the sequential assembly of the respective repeat unit associated with an endogenous lipid, very likely a diphosphate phenol, as well as the polymerization process that follows, leading to the formation of the final polysaccharide (Ielpi et al., $1981 a$, 1993). The incorporation of acetyl and ketal pyruvate residues at the prenyl phospho-sugar stage, from acetyl CoA and phosphoenol pyruvate, respectively, has been demonstrated also (Ielpi et al., 1981 b, 1983).

In this paper the in vitro synthesis of acetan is 


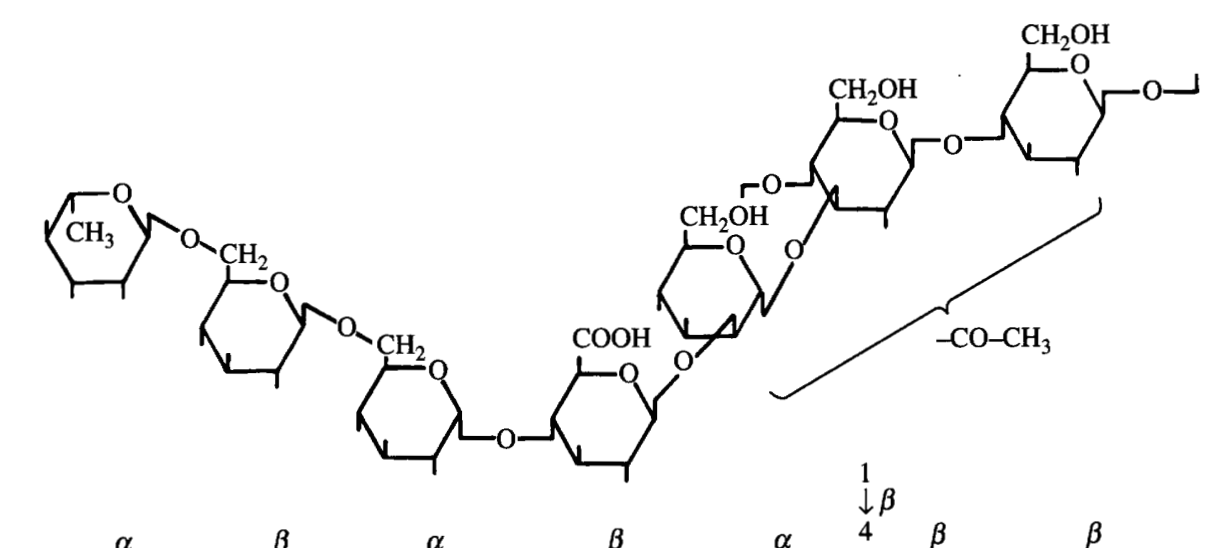

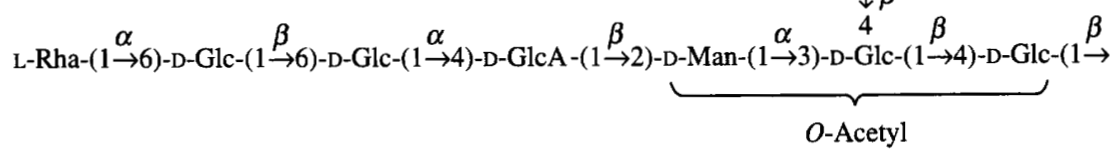

Fig. 1. Structure proposed for the repeat unit of acetan (Couso et al., 1987; Jansson et al., 1993).

described using a novel enzymic system: electroporated Acetobacter xylinum cells. Furthermore, the previously suggested precursor-product relationship between lipidlinked heptasaccharide and acetan is confirmed by means of two-step incubations.

The incorporation of $\left[{ }^{14} \mathrm{C}\right]$ acetyl residues into lipidlinked precursors, already detected employing EDTAtreated cells (R. O. Couso and M. A. Dankert, unpublished observations), as well as into acetan, confirmed previous observations (Jansson et al., 1993).

The formation of other side-products, not related to acetan synthesis, like lipid-bound glucuronic acid (Couso et al., 1986), prenyl monophosphate mannose (Couso et al., 1980), prenyl monophosphate galactose (García et al., 1974; Romero et al., 1977a), cellulose (Ross et al., 1991; Delmer, 1983) and glucan (García et al., 1974) was also observed with this system. The latter was detected in at least two stages, free and associated with a protein.

\section{Methods}

Chemicals. UDP- $\left[{ }^{14} \mathrm{C}\right] \mathrm{Glc}\left(200-300 \mathrm{Ci} \mathrm{mol}^{-1} ; 7 \cdot 4-11 \cdot 4 \mathrm{TBq} \mathrm{mol}{ }^{-1}\right)$, UDP- $\left[{ }^{14} \mathrm{C}\right] \mathrm{GlcA} \quad\left(200-300 \mathrm{Ci} \mathrm{mol}^{-1} ; \quad 7 \cdot 4-11.4 \mathrm{TBq} \mathrm{mol}^{-1}\right)$, GDP$\left[{ }^{14} \mathrm{C}\right] \mathrm{Man}\left(250-300 \mathrm{Ci} \mathrm{mol}^{-1} ; 9 \cdot 25-11 \cdot 4 \mathrm{TBq} \mathrm{mol}{ }^{-1}\right)$ and TDP- $\left[{ }^{14} \mathrm{C}\right] \mathrm{Rha}$ $\left(200-300 \mathrm{Ci} \mathrm{mol}^{-1} ; 7 \cdot 4-11.4 \mathrm{TBq} \mathrm{mol}^{-1}\right)$ were prepared as described previously (Couso et al., 1982). Radiolabelled glucose and $\left[{ }^{14} \mathrm{C}\right]$ acetyl $\mathrm{CoA}\left(55 \mathrm{Ci} \mathrm{mol}^{-1} ; 2.03 \mathrm{TBq} \mathrm{mol}^{-1}\right)$ were purchased from American Radiolabel Chemical Inc. (ARC) and $\left[{ }^{14} \mathrm{C}\right]$ Man from New England Nuclear. Tetra- and tri- $O$-methyl glucose derivatives and unlabelled acetan were obtained as described previously (Couso et al., 1987). $\left[{ }^{14} \mathrm{C}\right] \mathrm{GlcA}$-labelled hexasaccharide $\left(\mathrm{X}_{6}\right)$ and heptasaccharide $\left(\mathrm{X}_{7}\right)$, used as standards, were obtained from the respective lipid-linked derivatives, as reported previously (Couso et al., 1982). Acetylated cellobiose and acetylated mannosyl cellobiose, used as standards, were synthesized in incubations performed in the presence of acetyl CoA, either ${ }^{14} \mathrm{C}$ labelled or unlabelled and UDP-Glc (also either ${ }^{14} \mathrm{C}$-labelled or unlabelled) alone or plus GDP-Man, as reported previously (García et al., 1974; Couso et al., 1980; R. O. Couso and others unpublished observations). The position and number of the acetyl residues is not known. All other chemicals were commercial products.
Bacterial strains and culture media. The acetan-forming strain RCGr1, a derivative from strain NRRL B42 (Iñon de Iannino et al., 1988) was used throughout this work.

Bacteria were grown and freed from cellulose as described by Hestrin \& Schramm (1954). The cell suspension was centrifuged and the supernatant saved for isolation of acetan. The cell pellet was used either to obtain EDTA-treated cells as described previously by García et al. (1974) or to prepare cells for electroporation. In the latter case they were washed twice with $10 \%(\mathrm{v} / \mathrm{v})$ glycerol and resuspended in the same solution $(0.65 \mathrm{ml}$ for an original culture volume of $200 \mathrm{ml}$, to a final concentration of 8-10 $\mathrm{mg}$ protein $\mathrm{ml}^{-1}$ ).

Starved cells were obtained by resuspending the cell precipitate in $10 \mathrm{~mm}$-sodium phosphate buffer, $\mathrm{pH} 7.0$ (one half, $100 \mathrm{ml}$, of the original culture volume). They were incubated at $28^{\circ} \mathrm{C}$ for $30 \mathrm{~min}$, with shaking and then centrifuged, washed once with water and resuspended in water $(0.65 \mathrm{ml}$ for an original culture volume of $200 \mathrm{ml})$.

Electroporation of cells and standard incubation. The following amounts (nmol) of the different sugar nucleotide precursors were added to freshly prepared Acetobacter cells, either starved or not (about $1 \mathrm{mg}$ protein), in a $0.4 \mathrm{ml}$ electroporation cell: UDP-Glc, 24; UDP-GlcA, 24; GDP-Man, 30; TDP-Rha, 9.6.

As indicated in each case, one of the precursors was replaced by the following amounts (pmol) of the corresponding labelled nucleotide: UDP- $\left[{ }^{14} \mathrm{C}\right] \mathrm{Glc}, \quad 0.69 \quad\left(10^{6}\right.$ c.p.m. $) ; \quad$ UDP- $\left[{ }^{14} \mathrm{C}\right] \mathrm{GlcA}, \quad 0.41 \quad(0.6 \times$ $10^{6}$ c.p.m.); GDP- $\left[{ }^{14} \mathrm{C}\right]$ Man, $0.42\left(0 \cdot 6 \times 10^{6}\right.$ c.p.m. $)$ and TDP- $\left[{ }^{14} \mathrm{C}\right] \mathrm{Rha}$, $0.41\left(0.6 \times 10^{6}\right.$ c.p.m. $)$. Where indicated, $\left[{ }^{14} \mathrm{C}\right]$ acetyl $\mathrm{CoA}(2.7 \mathrm{pmol}$; $0.76 \times 10^{6}$ c.p.m.) was also added. In each case the final volume was brought to $0.15 \mathrm{ml}$ with water and kept at $0{ }^{\circ} \mathrm{C}$. Electroporation was performed at $1500 \mathrm{~V}, 400 \Omega$ and $25 \mu \mathrm{F}$ with a Gen Pulser Transfection Apparatus (Bio-Rad). Usually the resulting time constant was 7.0-8.2.

The solution was then transferred quickly to incubation vials containing Tris/ $\mathrm{HCl}, \mathrm{pH} 8.2$ and $\mathrm{MgCl}_{2}$ to reach final concentrations of 70 and $10 \mathrm{~mm}$, respectively, in a total volume of $0.20 \mathrm{ml}$. Incubations were at $30^{\circ} \mathrm{C}$ for $60 \mathrm{~min}$. They were ended by adding $0.005 \mathrm{ml} 250 \mathrm{~mm}$ EDTA adjusted to $\mathrm{pH} 8.0$ by the addition of $2 \mathrm{M}$-Tris to chelate the $\mathrm{Mg}^{2+}$ essential for activity of the sugar transfer enzymes (Garcia et al., 1974).

Two-step incubations. The first incubation was performed as described for the standard incubations, but at $10^{\circ} \mathrm{C}$, for $30 \mathrm{~min}$. The reaction was stopped by adding $250 \mathrm{~mm}$-EDTA-Tris, $\mathrm{pH} 8 \cdot 0(0.005 \mathrm{ml})$, and the cell resuspension was centrifuged in a tabletop Eppendorf centrifuge for $2 \mathrm{~min}$ at 10000 r.p.m. The cell pellet was then washed three times with $70 \mathrm{~mm}$-Tris/ $\mathrm{HCl}$ buffer, $\mathrm{pH} 8.2$, and resuspended in 
water $(0.1 \mathrm{ml})$. The washings were combined with the incubation supernatant and saved for analysis (fraction 1, acetan).

Half of the resuspended cells was saved for analysis (first pellet) and to the other half Tris $/ \mathrm{HCl}$ buffer, $\mathrm{pH} 8 \cdot 2$, and $\mathrm{MgCl}_{2}$ were added to bring their final concentrations to 70 and $10 \mathrm{~mm}$, respectively, in a final volume of $0.075 \mathrm{ml}$. The second incubation, with no additions, was at $30^{\circ} \mathrm{C}$ for $2 \mathrm{~h}$

Fractionation of the incorporation products. For each incubation vial, five fractions were obtained, i.e. ten fractions for two-step incubations. The reactions were ended by adding $250 \mathrm{~mm}$-EDTA-Tris, $\mathrm{pH} 8.0$ $(0.005 \mathrm{ml}$ to each incubation vial). The cells were spun down and washed three times with $70 \mathrm{~mm}$-Tris/ $\mathrm{HCl}$ buffer $(0.2 \mathrm{ml}$ each). The washings were combined with the incubation supernatants (fraction 1 , acetan). In the standard incubations and in the first step of the two-step incubations, this fraction contains the excess of sugar nucleotides and water-soluble products liberated during the incubation period, such as exopolysaccharide (EPS). This fraction (1) was freed from the excess of nucleotides as follows: it was brought to $\mathrm{pH} 2$ with $\mathrm{HCl}$, heated at $100^{\circ} \mathrm{C}$ for $10 \mathrm{~min}$ and then dialysed against $20 \mathrm{~mm}$-Tris $/ \mathrm{HCl}$ buffer (41) for $4 \mathrm{~h}$ at $4{ }^{\circ} \mathrm{C}$, changing to fresh buffer every hour. Then it was dialysed against deionized water at $4{ }^{\circ} \mathrm{C}$ for $36-48 \mathrm{~h}$, with two changes for fresh water. The dialysed material was analysed by filtering through a Bio-Gel Agarose A $5 \mathrm{~m}$ column (only acetan was detected). In the second step of the two-step incubations this fraction contains the water-soluble products liberated during the second incubation. It was directly analysed by filtering through a Bio-Gel A $5 \mathrm{~m}$ column (fraction 6 , acetan and other saccharides).

The washed cell pellets were then extracted three times $(0.2 \mathrm{ml} \mathrm{each})$ with chloroform/methanol/water $(1: 2: 0 \cdot 3$, by vol.; 1203 solvent $)$ and the extracts combined (1203 extract; fractions 2 and 7$)$. These fractions contain all the lipid-linked sugars formed, that may differ according to the labelled precursor used. It may also contain part of the glucan formed. The 1203-extracted pellets were then washed with water three times $(0.2 \mathrm{ml}$ each) and the washings combined (water washings, fractions 3 and 8). These fractions contain water-soluble compounds liberated after the disruption of the cell membranes produced by the 1203 solvent extraction. They contain glucan and lipid-linked oligosaccharide degradation products. The 1203-extracted and waterwashed cell precipitates were then resuspended in $1 \%(\mathrm{w} / \mathrm{v}) \mathrm{NaOH}$ $(0.1 \mathrm{ml})$ and heated at $100^{\circ} \mathrm{C}$ for $5 \mathrm{~min}$, a classical alkaline treatment to isolate cellulose as an insoluble material, since other polysaccharides are soluble (Elbein et al., 1966). After spinning down, a supernatant (fractions 4 and 9) and a pellet (cellulose, fractions 5 and 10) were obtained. Samples of each fraction were counted for radioactivity.

Radioactivity was counted in Bray's solution (Bray, 1960) with a 1214 Rackbeta Wallac Liquid Scintillation Counter.

Gel filtration. The Bio-Gel A $5 \mathrm{~m}$ (100-200 mesh) column (35× $1.2 \mathrm{~cm})$ and the Bio-Gel P2 $(200-400$ mesh) column $(90 \times 1 \mathrm{~cm})$ were eluted with $0.1 \mathrm{M}$-pyridinium acetate buffer, $\mathrm{pH} 5.0$ at a rate of $0.1 \mathrm{ml} \mathrm{min}^{-1}$, collecting $0.5 \mathrm{ml}$ fractions.

Blue Dextran and $\mathrm{CoCl}_{2}$ were used as indicators of total exclusion and inclusion volumes, respectively.

Column chromatography. DEAE-cellulose (Whatman) column chromatography $(54 \times 1.5 \mathrm{~cm})$ was performed at room temperature with $99 \%$ methanol as solvent at a rate of $20 \mathrm{ml} \mathrm{h}^{-1}$, collecting $3 \mathrm{ml}$ fractions. After fraction 33 a linear gradient of 0-2 M-ammonium acetate in $99 \%$ methanol was applied as described previously (Dankert et al., 1966).

Methylation analysis. The method of Hakomori was used, as described by Sandford \& Conrad (1966). The samples were processed as in previous work (Couso et al., 1987).

Acid hydrolysis. Sugar-phosphate linkages were hydrolysed by heating at $\mathrm{pH} 2(0.01 \mathrm{M}-\mathrm{HCl}), 100^{\circ} \mathrm{C}$ for $10 \mathrm{~min}$ as reported previously
(García et al., 1974), and total acid hydrolysis of oligosaccharides and polysaccharides was performed in $1.0 \mathrm{M}-\mathrm{HCl}$, at $100^{\circ} \mathrm{C}$ for $20-24 \mathrm{~h}$ in a sealed tube.

Borohydride reduction was carried out as described by Couso et al. (1987).

$\alpha$-Amylase treatment. The incubations were performed in $100 \mathrm{~mm}$ Tris/ $\mathrm{HCl}$ buffer, $\mathrm{pH} 7 \cdot 4$, containing $50 \mathrm{mM}-\mathrm{CaCl}_{2}, 0.22$ units of enzyme [ $2 \mathrm{mg} \mathrm{ml}^{-1}, 2124$ units $\mathrm{mg}^{-1}$ kindly provided by Dr C. Krisman (this Institute)] and substrate in a total volume of $0.1 \mathrm{ml}$ at $37^{\circ} \mathrm{C}$ for $48 \mathrm{~h}$ in a toluene atmosphere.

Chromatography and electrophoresis. Paper chromatography and electrophoresis were done using Whatman No. 1 paper as described previously (Garcia et al., 1974). The following solvents were used: A, propan-2-ol/acetic acid/water (27:4:9, by vol.); B, butan-1-ol/ pyridine/water (6:4:3, by vol.); C, 1.2 M-pyridinium acetate buffer, pH 6.5; D, 0.1 M-sodium molybdate buffer, pH 5.0.

Reducing substances were located with alkaline silver nitrate (Trevelyan et al., 1950) and radioactive areas with a radiochromatogram scanner (Packard, model 7201). UV-absorbing compounds were detected with a Mineralight UV lamp.

TLC was performed on silica gel $G$ plates $(250 \mu \mathrm{m}$ thick, Merck) in solvent $\mathrm{E}$, benzene/acetone/water $/ \mathrm{NH}_{4} \mathrm{OH}$ (sp. gr. 0.91) $(50: 200: 1 \cdot 0: 1 \cdot 35$, by vol.).

The non-radioactive samples were located by spraying with $5 \%(\mathrm{v} / \mathrm{v})$ $\mathrm{H}_{2} \mathrm{SO}_{4}$ in ethanol and heating at $120^{\circ} \mathrm{C}$ for $10 \mathrm{~min}$ ( $\mathrm{Li}$ et al., 1978). Labelled compounds were located by radioscanning as above, or by autoradiography using Kodak X-Omat A-R film (X-AR-5).

\section{Results}

\section{Analysis of the incorporation products}

Previous studies have shown that in incubations performed at $30^{\circ} \mathrm{C}$ with EDTA-treated Acetobacter xylinum cells, UDP- $\left[{ }^{14} \mathrm{C}\right] \mathrm{GlcA}$ and the other unlabelled sugar nucleotides, the radioactive products in 1203 extracts consisted of prenyldiphosphate heptasaccharide and a lipid-bound glucuronide (Couso et al., 1982, 1986).

Similar experiments have now been performed, but using electroporated cells as enzyme source, and good incorporation of radioactivity into the 1203 extracts (fraction 2) has been obtained also. Analysis by DEAEcellulose column chromatography of these extracts showed the formation of both compounds mentioned above: lipid-bound glucuronic acid (compound I, eluted at $0.7 \mathrm{M}$-ammonium acetate) and the prenyl diphosphate oligosaccharide (compound II, eluted at $1.1 \mathrm{M}$ ammonium acetate) (Fig. 2).

These results prompted a systematic system of the incubation conditions to detect polymer formation. To simplify the analysis of the 1203 extracts, they were not chromatographed on DEAE-cellulose columns but submitted to paper electrophoresis either untreated or after hydrolysis at $\mathrm{pH} 2$.

Preliminary incubations were performed in the presence of UDP- $\left[{ }^{14} \mathrm{C}\right] \mathrm{GlcA}$, and the other donors unlabelled, at different temperatures $\left(0-30^{\circ} \mathrm{C}\right)$. Good incorporations into the 1203 extracts (fraction 2), that increased with 


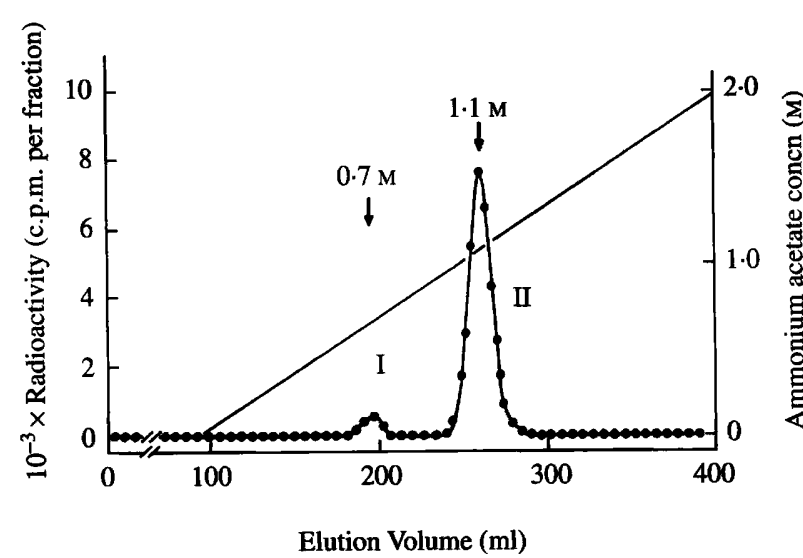

Fig. 2. DEAE-cellulose column chromatography of a $\left[{ }^{14} \mathrm{C}\right] \mathrm{GlcA}$ labelled 1203 extract. The 1203 extract ( 300000 c.p.m.) was prepared in a four-fold standard incubation at $30^{\circ} \mathrm{C}$. The column was run as described in Methods, collecting $3 \mathrm{ml}$ fractions. After fraction 33, the 0-2 M-ammonium acetate gradient was connected. Samples $(0.3 \mathrm{ml})$ were counted for radioactivity. The numbers on top of the peaks indicate the elution concentration. Compound I: lipid-bound glucuronic acid; compound II: prenyl diphosphate oligosaccharide.

\section{Table 1. Effect of the incubation temperature on the incorporation of $\left[{ }^{14} \mathrm{C}\right] \mathrm{GlcA}$}

The incubations were performed as for the standard assay but with unlabelled UDP-Glc, GDP-Man and TDP-Rha (16.5 nmol each) and UDP- $-\left[{ }^{14} \mathrm{C}\right] \mathrm{GlcA}\left(0.19 \mathrm{pmol} ; 0.28 \times 10^{6}\right.$ c.p.m. $)$ in a final volume of $0.20 \mathrm{ml}$, at the indicated temperatures, for $60 \mathrm{~min}$. To isolate the polymer fraction, the incubation supernatants (Fraction 1) were processed as indicated in Methods. The Bio-Gel A $5 \mathrm{~m}$ filtrates eluting in the position of the acetan carrier, were pooled and counted for radioactivity (Polymer). See Fig. 4.

\begin{tabular}{cccccc}
\hline & \multicolumn{3}{c}{ Incorporation of $\left[{ }^{14} \mathrm{C}\right] \mathrm{GlcA}$} \\
\cline { 2 - 3 } $\begin{array}{c}\text { Temperature } \\
\left({ }^{\circ} \mathrm{C}\right)\end{array}$ & \multicolumn{2}{c}{ Polymer* } & & \multicolumn{2}{c}{1203 extract* } \\
\cline { 2 - 3 } \cline { 5 - 6 } & (c.p.m.) & (pmol) & & (c.p.m.) & (pmol) \\
\hline 0 & $<30$ & $<0.06$ & & 17060 & 33.40 \\
10 & $<30$ & $<0.06$ & & 26100 & 51.28 \\
20 & 1000 & 1.96 & & 33630 & 66.07 \\
30 & 3600 & 7.07 & & 55000 & 108.01 \\
$30 \dagger$ & $<30$ & $<0.06$ & & 66240 & 130.35 \\
\hline \hline
\end{tabular}

* The numbers indicate either c.p.m. or pmol GlcA (mg protein) ${ }^{-1}$, on the basis of the specific activity of the $\left[{ }^{14} \mathrm{C}\right] \mathrm{GlcA}$.

$\dagger$ In this case EDTA-treated cells were used as enzyme preparation.

incubation temperature, were obtained (Table 1). Analysis of the extract obtained at $30^{\circ} \mathrm{C}$ showed that, as expected, the radioactivity was associated to lipids since upon paper electrophoresis it remained at the origin of the run (Fig. $3 a$ ). Mild acid hydrolysis $\left(\mathrm{pH} 2,100^{\circ} \mathrm{C}\right.$, $10 \mathrm{~min}$ ) of the 1203 extract released all the radioactivity in two water-soluble compounds that, upon paper electrophoresis, behaved as the heptasaccharide repeat unit $\left(R_{\mathrm{UMP}}=0.5\right)$ and as free $\left[{ }^{14} \mathrm{C}\right] \mathrm{GlcA}$, as reported previously (Couso et al., 1982) (Fig. 3b). Gel filtration of

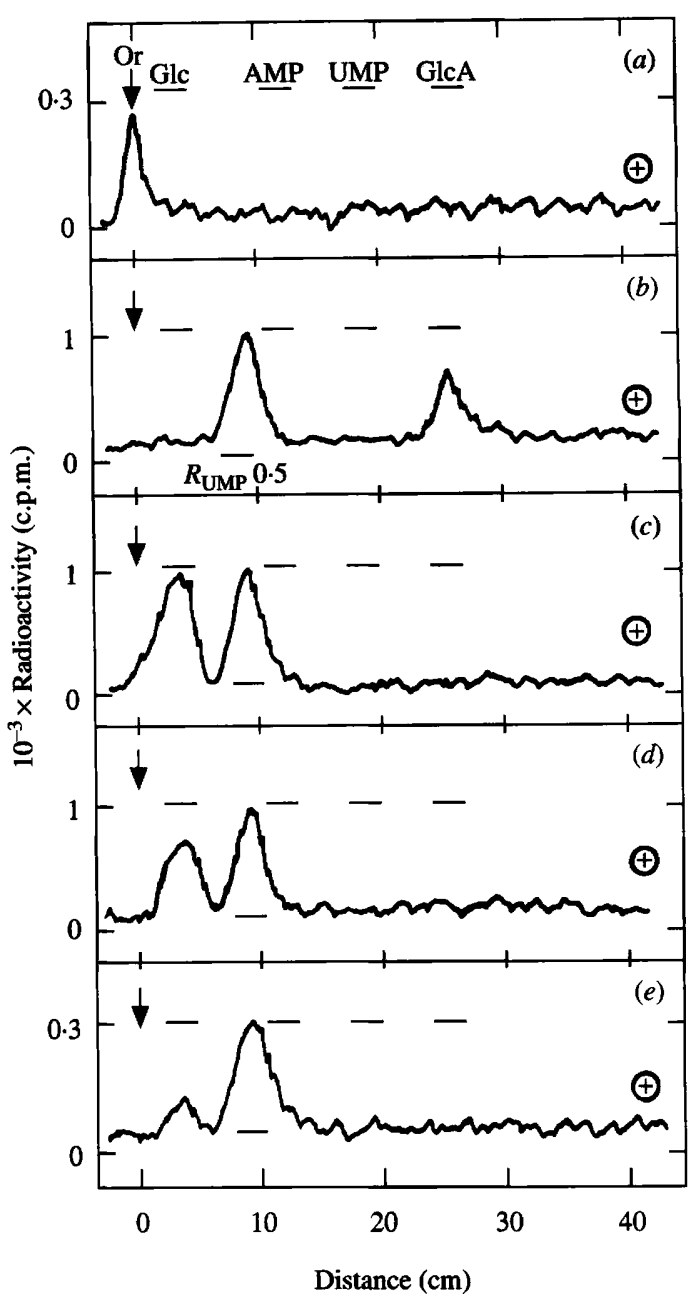

Fig. 3. Analysis of 1203 extracts. Aliquots of the 1203 extract, obtained at $30^{\circ} \mathrm{C}$ as described in the legend to Table 1 , were submitted to paper electrophoresis with buffer $\mathrm{C}$ either untreated (5000 c.p.m.) (a) or after hydrolysis at $\mathrm{pH} 2\left(0.01 \mathrm{M}-\mathrm{HCl}, 100^{\circ} \mathrm{C}, 10 \mathrm{~min}\right)(28000$ c.p.m. $)(b)$. Mild-acid-treated ( $\mathrm{pH}$ 2) 1203 extracts from incubations performed in the presence of UDP- $\left[{ }^{14} \mathrm{C}\right] \mathrm{Glc}\left(50000\right.$ c.p.m.) (c), GDP- $\left[{ }^{14} \mathrm{C}\right] \mathrm{Man}$ $\left(35000\right.$ c.p.m.) $(d)$, and TDP- $\left[{ }^{14} \mathrm{C}\right]$ Rha $(9500$ c.p.m.) $(e)$ were submitted to paper electrophoresis as above. Glc, AMP, UMP and GlcA were added as mobility standards. Glc mobility was considered to be that of neutral compounds. Or, origin.

the former compound indicated that in addition to the heptasaccharide some hexasaccharide (the repeat unit without the terminal rhamnose) was also present (about $30 \%$ ) (Fig. 4). The identity of the $\left[{ }^{14} \mathrm{C}\right] \mathrm{GlcA}$ was confirmed by paper electrophoresis with buffer $D$.

Similar results were observed by analysing the 1203 extracts obtained at the other temperatures indicated in Table 1 (not shown).

The incubation supernatants (fraction 1) from the different incubation temperatures were processed as indicated in Methods. At $30^{\circ} \mathrm{C}$, incorporation of radioactivity into a polymer that coeluted with carrier acetan was evident (Fig. 5a). Polymer formation was not 


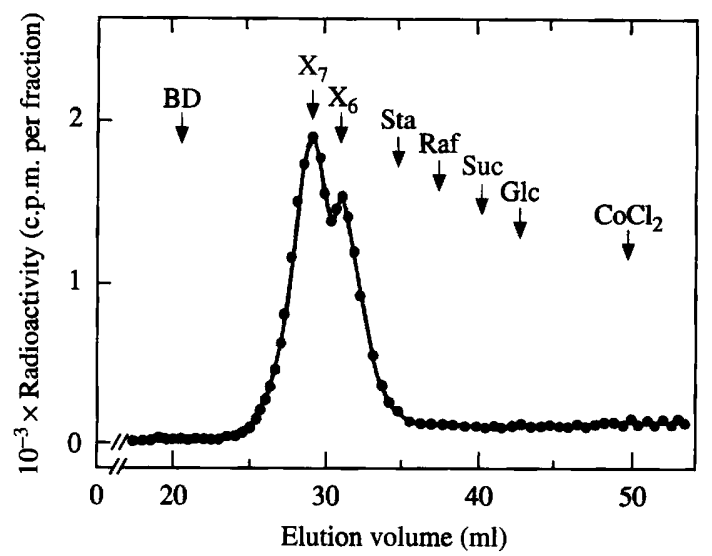

Fig. 4. Bio-Gel P2 gel filtration. The compound of $R_{\mathrm{UMP}}=0.5$ from Fig. 3(b) (about 15000 c.p.m.) was eluted from the electrophorogram and filtered through a Bio-Gel P2 column as indicated in Methods. The arrows indicate the elution position of glucose (Glc), sucrose (Suc), raffinose (Raf) and stachiose (Sta) added as standards of mono-, di-, tri- and tetrasaccharides, respectively, detected by the phenol- $\mathrm{H}_{2} \mathrm{SO}_{4}$ method (Smith \& Montgomery, 1956); $X_{6}$ and $X_{7}$, hexa- and heptasaccharide repeat units from A. xylinum. BD, Blue Dextran and $\mathrm{CoCl}_{2}$ were added as indicators of total exclusion and inclusion volumes, respectively.

detected below $20^{\circ} \mathrm{C}$. These results are summarized in Table 1, that, in addition, shows a control experiment performed at $30^{\circ} \mathrm{C}$ under the same conditions but using EDTA-treated cells. Although a slightly higher incorporation of radioactivity into 1203 extract was observed, no polymer formation was detected, as reported in previous publications (Couso et al., 1982; Iñon de Iannino et al., 1988). Mild acid hydrolysis of this 1203 extract, upon paper electrophoresis, produced a similar radioactive profile as in Fig. $3(b)$, as expected.

These results also showed that using UDP- $\left[{ }^{14} \mathrm{C}\right] \mathrm{GlcA}$ as labelled precursor, the only polymer formed was acetan (Fig. $5 a$ and Table 2).

\section{Incorporation of the other components of acetan}

To confirm that the polymer formed was acetan, incorporation studies similar to the above described were performed using all the different sugars precursors, labelled one at a time. The results are summarized in Table 2. The profiles obtained upon paper electrophoresis of the mild-acid-treated 1203 extracts (fraction 2) confirm previous results obtained with EDTA-treated cells; for each label the main compound detected was the heptasaccharide repeat unit $\left(R_{\mathrm{UMP}}=0.5\right)$ (Fig. $\left.3 c, d, e\right)$. Bio-Gel A $5 \mathrm{~m}$ gel filtration of the incubation supernatants showed that all the sugars were incorporated only into the acetan fraction although in different apparent amounts (Table 2, fraction 1 and Fig. $5 a, b$ ). The differences observed are possibly due to the presence

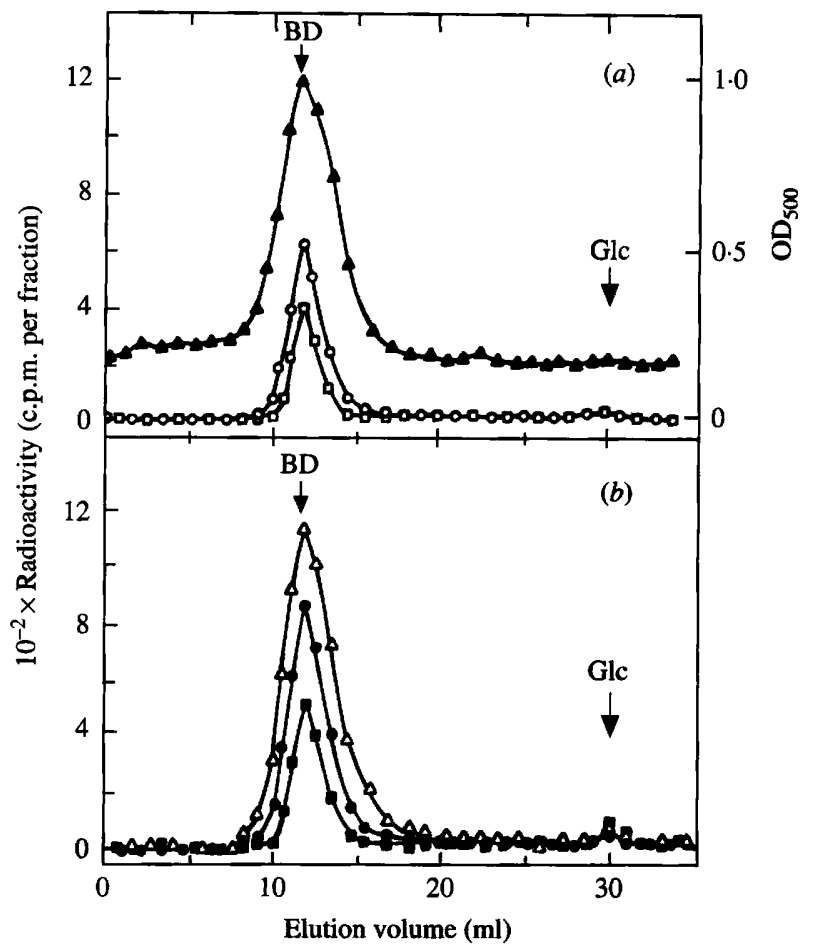

Fig. 5. Agarose gel filtration. The incubations were performed under standard conditions, with one labelled sugar nucleotide at a time, and the supernatants (fraction 1) were processed as indicated in Methods. After the dialysis step they were concentrated down to $0.2 \mathrm{ml}$ under vacuum and filtered through a Bio-Gel A $5 \mathrm{~m}$ column, at room temperature (see Methods). When the label was UDP- $\left[{ }^{14} \mathrm{C}\right] \mathrm{GlcA}$, the incubation conditions were those described in the legend to Table 1 , and to the respective dialysed fraction 1 , unlabelled acetan $(0.5 \mathrm{mg}$ in $0.5 \mathrm{ml}$ ) was added as internal standard. Although for each label a different column was run, the profiles obtained are shown in two panels for the sake of comparison. For each label the amounts used were: $(a)$ $\left[{ }^{14} \mathrm{C}\right]$ Rha (1200 c.p.m., $\square$ ), $\left[{ }^{14} \mathrm{C}\right]$ GlcA (3600 c.p.m., O) and unlabelled acetan (A) located by the phenol- $\mathrm{H}_{2} \mathrm{SO}_{4}$ method (Smith \& Montgomery, 1956); (b) $\left[{ }^{14} \mathrm{C}\right] \mathrm{Man}(2500$ c.p.m., $\mathbf{0}),\left[{ }^{14} \mathrm{C}\right] \mathrm{Glc}$ (4600 c.p.m., ) and $\left[{ }^{14} \mathrm{C}\right]$ acetate. $(8700$ c.p.m., $\triangle)$. The arrows indicate the elution volume position of known standards. BD, Blue Dextran.

of endogenous donors and acceptors in the enzyme preparations used. From experience with EDTA-treated cells it is known that they contain endogenous donors and acceptors. The donors can be partially removed by dialysis, but not the acceptors, that very likely are closely associated to the cell membrane (Ielpi et al., 1993). With electroporated cells the situation should be similar.

To reduce the amount of donors and acceptors, the washed cells were incubated for different periods of time in a buffer without nutrients but with aeration, to allow them to consume their reserves (starved cells).

Cells electroporated after $30 \mathrm{~min}$ starvation showed increased incorporation of radioactivity into most fractions (Table 2). With shorter or longer times of starvation, the increment of radioactivity incorporated into the polymer was smaller. The increase in incor- 


\section{Table 2. Incorporation of the acetan components into the different fractions analysed}

Standard incubations were performed in the presence of the indicated ${ }^{14} \mathrm{C}$-labelled precursor and the incorporation products were fractionated, as indicated in Methods. Incorporation is expressed as c.p.m. (mg protein) ${ }^{-1}$. Some of the compounds included in the 'other' columns were identified as indicated below. Abbreviation: Hepta, prenyl diphosphate hexa-heptasaccharide.

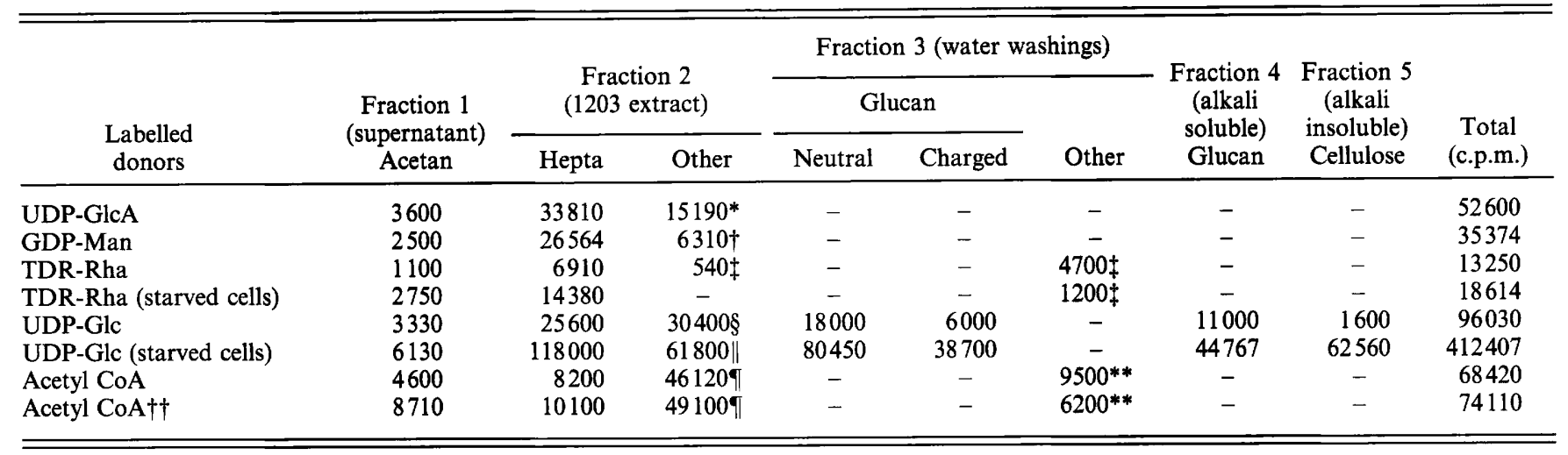

${ }^{*}$ Lipid-bound glucoronic acid (Couso et al., 1986).

$\dagger$ Prenyl monophosphate mannose (Couso et al., 1980).

$\ddagger$ Unidentified $\left[{ }^{14} \mathrm{C}\right] \mathrm{R}$ ha-containing compounds.

$\S$ Glucan (8300 c.p.m.) (Garcia et al., 1974), prenyl monophosphate galactose (16200 c.p.m.) (Romero et al., 1977 a) and an unidentified product (6080 c.p.m.).

\| Glucan (29000 c.p.m.) (Garcia et al., 1974), prenyl monophosphate galactose (15800 c.p.m.) (Romero et al., 1977a) and an unidentified product (17000 c.p.m.).

I Prenyl diphosphate acetyl cellobiose, prenyl diphosphate acetyl mannosyl cellobiose and their degradation products, the cyclic phosphate esters of acetyl cellobiose and of acetyl mannosyl cellobiose (García et al., 1974; Couso et al., 1980; R. O. Couso and M. A. Dankert, unpublished observations).

** Cyclic phosphate esters of acetylated cellobiose and mannosyl cellobiose, as above.

t† Incubation in the presence of unlabelled sugar nucleotide donors.

porated radioactivity observed was possibly due in part to the decrease in endogenous donors that isotopically diluted the labelled sugar nucleotide donor. Since the specific activity of the incorporation products was not determined, the increase in sugar incorporation observed may be more apparent than real (Table 2).

In contrast, recent studies have shown that acetan also contains about $4.0 \%$ acetate ester residues (R. O. Couso \& M. A. Dankert, unpublished results; Jansson et al., 1993). The incorporation of labelled acetate into the different fractions under study was then investigated using $\left[{ }^{14} \mathrm{C}\right]$ acetyl $\mathrm{CoA}$ as donor. Even in the absence of unlabelled sugar nucleotide donors, $\left[{ }^{14} \mathrm{C}\right]$ acetate was detected in the polymer fraction and this incorporation was almost doubled in the presence of the unlabelled sugar donors (Table 2, Fraction 1 and Fig. 5b). As expected $\left[{ }^{14} \mathrm{C}\right]$ acetate was also detected in the 1203 extracts (Table 2, Fraction 2). The prenyl diphosphate hexa-heptasaccharide was clearly labelled, but most of the radioactive substances were degraded (fraction 2 , other). This subfraction 'other' contained neutral and negatively charged components. Analysed by Bio-Gel P2 gel filtration and paper chromatography with solvent $\mathrm{A}$, the neutral components $(27500$ c.p.m.) were characterized as a mixture of acetylated cellobiose and mannosyl cellobiose. In a similar way the negatively charged fraction ( 21600 c.p.m.), as well as the water-soluble charged component (6200 c.p.m.) (fraction 3, other) were found to be a mixture of the cyclic phosphate esters of acetylated cellobiose and mannosyl cellobiose. Similar results were obtained with the respective fractions from incubations without sugar nucleotide donors (Table 2). The accumulation of lipid-linked intermediates at this stage is not understood.

The main point of these series of experiments is that, for each label, the profile obtained after Bio-Gel A $5 \mathrm{~m}$ gel filtration of the incubation supernatant fraction (fraction 1) showed a single peak with the same elution volume as unlabelled acetan (Fig. 5). Furthermore, permethylation analysis of the $\left[{ }^{14} \mathrm{C}\right]$ Glc-labelled acetan showed the formation of the expected derivatives: 2,6-di$O$-methyl-glucose, derived from the branching sugar 2,3,4-tri- $O$-methyl-glucose, from the two $\beta$-1,6-substituted glucoses, and 2,3,6-tri- $O$-methyl-glucose, from the first glucose of the repeat unit. Surprisingly, small amounts of 2,3,4,6-tetra- $O$-methyl-glucose were also detected, indicating the presence of a terminal glucose. This latter result was interpreted as the consequence of the polymerization of hexasaccharide repeat units, lacking the terminal rhamnose (Fig. 6a).

This interpretation was also supported by the fact that when a similar permethylation analysis was performed on the $\left[{ }^{14} \mathrm{C}\right] \mathrm{Glc}$-labelled heptasaccharide fraction derived from mild acid hydrolysis of the 1203 extracts obtained 
(a)

Fig. 6. TLC analysis of the permethylation products. Samples of $\left[{ }^{14} \mathrm{C}\right] \mathrm{Glc}$ acetan (31000 c.p.m.) (a) and of $\left[{ }^{14} \mathrm{C}\right] \mathrm{Glc}$ oligosaccharide repeat unit $(20000$ c.p.m.) isolated by paper electrophoresis (as in Fig. 2c) (b) were permethylated and hydrolysed (see Methods) and the products analysed by TLC with solvent $\mathrm{E}$. The structures of an internal $(a)$ and of a free repeat unit $(b)$ show the origin of the different permethylated glucoses (solid lines), the numbers indicating the position of the methyl groups and the arrows, the respective mobilities. The dashed line corresponds to the terminal glucose originated when the rhamnose is absent and the asterisk (*) indicates the position of the branching sugar. $R$, rest of the acetan molecule; Or, origin; F, solvent front.

from incubations carried out in the presence of all the sugar donors, TDP-Rha among them, a fair amount of 2,3,4,6-tetra-O-methyl-glucose was consistently detected (Fig. 6b), confirming the presence of hexasaccharide observed by gel filtration (Fig. 4). As expected, in this case instead of 2,6-di- $O$-methyl-glucose, the 2,4,6-tri- $O$ methyl derivative was observed, since at this stage the repeat unit is still linear.

The presence of incomplete repeat units both at the acetan- and prenol-linked levels might simply reflect minor damage to the last transglycosylase enzyme produced during the in vitro manipulation. In contrast, it demonstrates the possibility of obtaining truncated polysaccharides. This opens the way to look for mutants that might produce new polysaccharides with, perhaps, interesting properties.

During these studies it was observed that with material obtained from unstarved cells the first two glucoses, at the reducing end of the repeat unit, were very difficult to label, indicating the presence of partially built lipidlinked repeat units working as endogenous acceptors (not shown). This difficulty was partially overcome when starved cells were used as enzyme source. For instance, only with these preparations a 1:6 sorbitol:glucose radioactivity ratio was obtained (instead of the theoretical $1: 3$ ratio) after total acid hydrolysis of borohydride-reduced hexa-heptasaccharide, showing that the reducing glucose had a specific activity smaller than the other glucoses. With material from unstarved cells, the sorbitol:glucose radioactivity ratio was higher than $1: 14$, indicating a still greater isotopic dilution of the reducing glucose. These results indicate that star- (b)

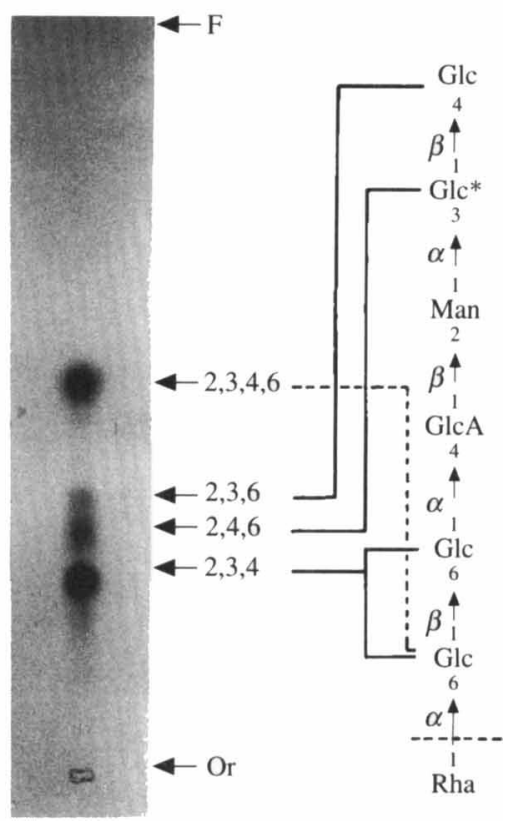

vation also reduces the amount of partially built repeat units, working as acceptors.

\section{Prenyl-linked oligosaccharides as intermediates in the synthesis of acetan}

To show that the 1203-solvent-soluble lipid-linked oligosaccharides are intermediates in the synthesis of acetan, a two-step incubation assay was carried out.

In the first step, in the presence of the four sugar nucleotide donors, one of them labelled, a standard incubation was performed, but at $10^{\circ} \mathrm{C}$, because at this temperature the polymerization process is highly diminished and the lipid-linked sugars accumulate (Table 1). The excess of sugar nucleotides was then removed by centrifugation and the washed cells were reincubated, this time at $30^{\circ} \mathrm{C}$, to allow polymerization.

The results are summarized in Table 3. For instance, using UDP- $\left[{ }^{[4} \mathrm{C}\right] \mathrm{GlcA}$ as labelled donor, from the prenyl diphosphate hexa-heptasaccharide mixture accumulated at the end of the first step $(21200$ c.p.m., fraction 2, hepta), about half of it remained as such (10100 c.p.m., fraction 7 , hepta) after the second incubation, but a significant amount (3000 c.p.m., fraction 6, acetan) was polymerized into acetan. In addition, free hexaheptasaccharides (6000 c.p.m., fraction 6, hepta) were also detected in this water phase. Furthermore, most of the lipid-bound GlcA released the sugar into this water phase (fraction 6 , other).

Using UDP- $\left[{ }^{14} \mathrm{C}\right] \mathrm{Glc}$ as marker, the distribution of radioactivity was more complex, but even so, easy to interpret. Again, the prenyl diphosphate hexa- 


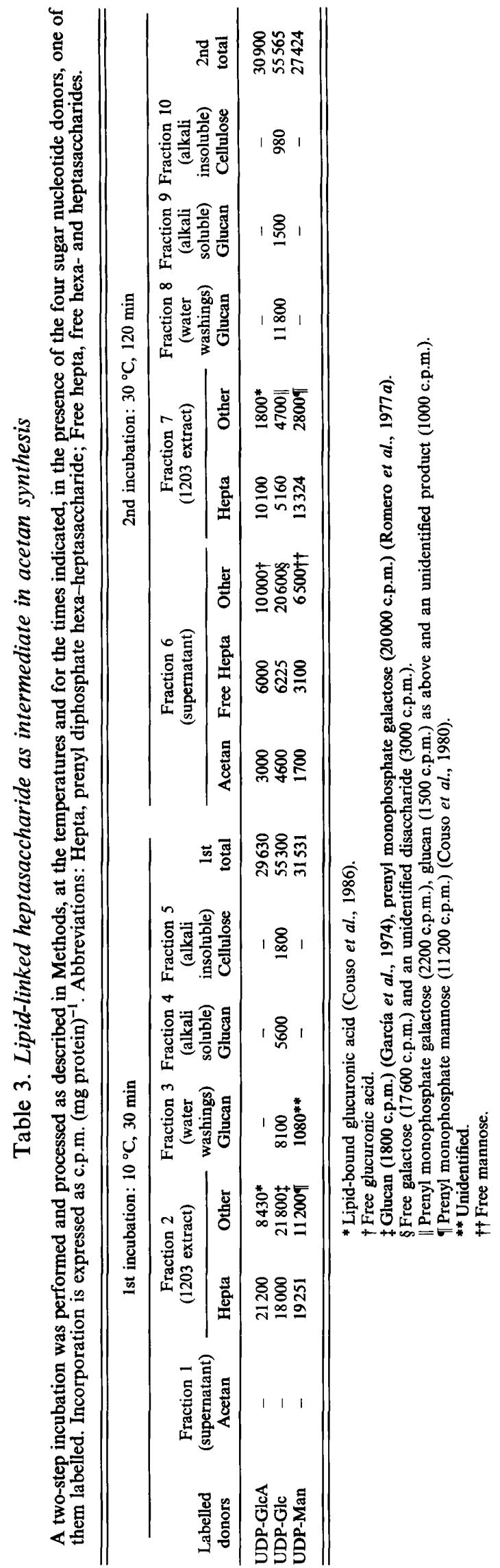

heptasaccharide accumulated during the first incubation (18000 c.p.m., fraction 2, hepta) followed three ways: about one-third of it remained as such (5160 c.p.m., fraction 7, hepta); another third was polymerized (4600 c.p.m., fraction 6, acetan) and the rest was liberated into the water layer as free hexaheptasaccharide (6225 c.p.m., fraction 6, hepta).

A similar correlation was observed with the Manlabelled precursor, although in this particular case, the amount of polymer formed was low. It should be stressed that in all these experiments, for each label, the radioactivity recovered at the end of the first and second incubations (Table 3, 1st and 2nd totals) were in reasonable agreement, especially considering the number of operations involved. The positive and negative differences obtained are within the experimental error.

Finally, with each label, the compounds not related to acetan biosynthesis were also detected in the respective fractions, as expected (Table 3).

\section{Sugar incorporation into compounds not related to acetan}

The in vivo formation of several lipid-linked sugars not related to acetan biosynthesis, like prenyl monophosphate galactose, prenyl monophosphate mannose and a lipid-bound glucuronic acid with unusual properties have been described in previous publications (Romero et al., 1977a; Couso et al., 1980, 1986). All have been detected in the present study (Table 2, fraction 2). Paper electrophoresis of the $\mathrm{pH}$ 2-treated 1203 $\left[{ }^{14} \mathrm{C}\right]$ GlcA-labelled extracts showed, in addition to the hexa-heptasaccharide $\left(R_{\mathrm{UMP}}=0.5\right)$, free $\left[{ }^{14} \mathrm{C}\right] \mathrm{GlcA}$, as mentioned above (Fig. 3b) (Couso et al., 1986) and DEAE-cellulose column chromatography of the untreated extracts clearly separated the intact prenyl diphosphate hexa-heptasaccharides (compound II) from the lipid-bound glucuronide (compound I) (Fig. 2).

In a similar way, $\left[{ }^{14} \mathrm{C}\right] \mathrm{Man}-$ and $\left[{ }^{14} \mathrm{C}\right]$ Glc-labelled $\mathrm{pH}$ 2-treated 1203 extracts produced significant radioactive neutral peaks (Fig. $3 c, d$ ). The $\left[{ }^{14} \mathrm{C}\right] \mathrm{Man}$ neutral compound was confirmed to be free $\left[{ }^{14} \mathrm{C}\right]$ Man derived from the hydrolysis of prenylmonophosphate mannose (Couso et al., 1980), but the composition of the $\left[{ }^{14} \mathrm{C}\right] \mathrm{Glc}$ neutral peak was more complex. Filtered through a BioGel A $5 \mathrm{~m}$ column, the profile obtained showed two main components. One was eluted at the position corresponding to a $500000 \mathrm{Da}$ molecular mass glucan. The other one corresponded to the total inclusion volume; it consisted of galactose originated in the hydrolysis of prenylmonophosphate galactose (Romero et al., 1977a) and of an unidentified disaccharide (Table 2, fraction 2, other). The glucan was not retained by filtration through a mixed bed ion-exchange Amberlite MB3 column. It 


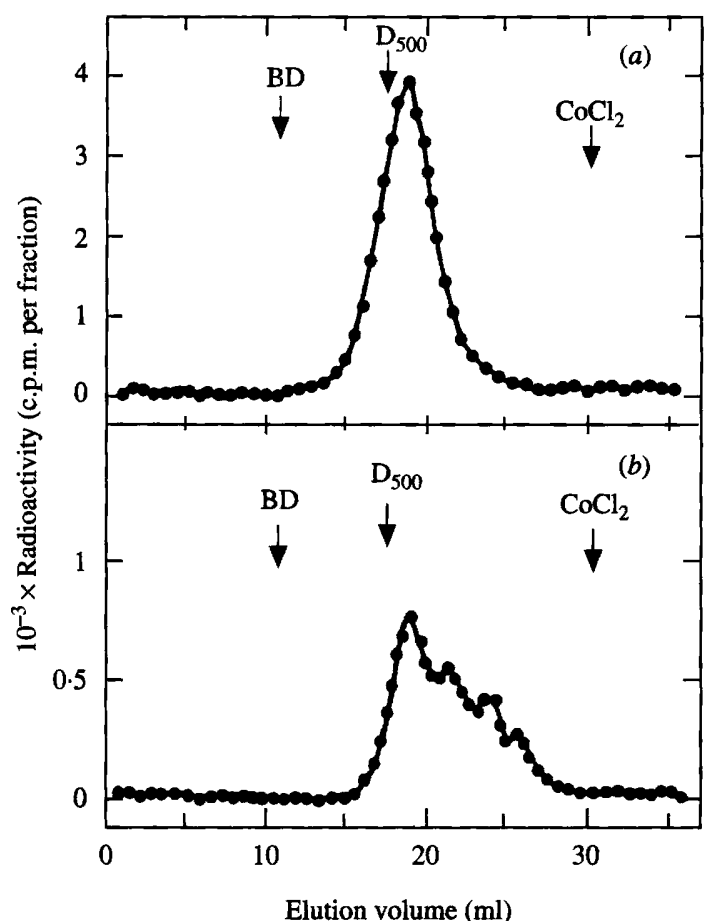

Fig. 7. Gel filtration of $\left[{ }^{14} \mathrm{C}\right]$ Glc-labelled fractions 3 and $4 .\left[{ }^{14} \mathrm{C}\right] \mathrm{Glc}$ labelled fraction 3 , containing both the neutral and charged components (34000 c.p.m.) (a), and fraction 4 similarly labelled (11000 c.p.m.) (b) (see Table 2) were filtered through a Bio-Gel A $5 \mathrm{~m}$ column. Fractions $(0.5 \mathrm{ml})$ were collected and $0.1 \mathrm{ml}$ samples counted for radioactivity. Blue Dextran (BD) and $\mathrm{CoCl}_{2}$ indicate total exclusion and inclusion volumes, respectively. $D_{500}$, Standard dextran of $5 \times 10^{5} \mathrm{Da}$ molecular mass.

was soluble in $5 \%(\mathrm{w} / \mathrm{v})$ TCA and not degraded by $\alpha-$ amylase treatment.

Furthermore, especially when working with UDP$\left[{ }^{14} \mathrm{C}\right] \mathrm{Glc}$ as labelled precursor, a series of labelled compounds have been detected in other fractions (Table 2). A water-soluble glucan (about 120000 c.p.m.), already observed in previous studies (García et al., 1974) was by far the most important component. Filtered through a Bio-Gel A $5 \mathrm{~m}$ column, this material produced a single peak of radioactivity with an apparent molecular mass of $500000 \mathrm{Da}$ (Fig. 7a), but when chromatographed through an Amberlite MB3 column it was seen to contain at least two components. One was neutral (80450 c.p.m.), since it was not retained by the column; and the other was eluted with $0.8 \mathrm{M}-\mathrm{NaCl}$, indicating the possession of some kind of charge ( 38700 c.p.m.) (Table 2 , fraction 3). This latter material was insoluble in $5 \%$ TCA, suggesting that it was associated with a protein. The neutral fraction was not precipitated by $5 \%$ TCA. Both fractions were insensitive to $\alpha$-amylase degradation.

In contrast, the radioactivity associated with the cell pellet after the 1203 solvent extraction and the water washings could be fractionated in two groups: an alkalisoluble fraction (44767 c.p.m.) (fraction 4), and a water- and alkali-insoluble fraction, estimated to be cellulose (62560 c.p.m.) (fraction 5), a characteristic product of this organism (García et al., 1974).

Filtered through a Bio-Gel A $5 \mathrm{~m}$ column, fraction 4 showed a complex profile with a maximum at a molecular mass around $500000 \mathrm{Da}$ and a series of lower peaks of smaller apparent molecular mass (Fig. $7 b$ ). It is very likely that fraction 4 was also associated with a protein because it was retained by filtration through an Amberlite MB3 column and more than $80 \%$ of the radioactivity was precipitated with $5 \%$ TCA. Fraction 4 was insensitive to $\alpha$-amylase degradation.

Partial acid hydrolysis $\left(0 \cdot 1 \mathrm{M}-\mathrm{HCl}, 100^{\circ} \mathrm{C}, 1 \mathrm{~h}\right)$ of all these glucan fractions produced free glucose and a series of oligosaccharides of decreasing size, as judged by paper chromatography with solvent $\mathrm{A}$. The smallest one was identified as glucosyl $(1 \rightarrow 2)$ - $\beta$-glucose, sophorose, upon borohydrate reduction and paper electrophoresis with buffer $\mathrm{D}$ (not shown).

In the two-step incubation experiment using UDP$\left[{ }^{14} \mathrm{C}\right]$ Glc as marker (Table 3) a new interesting point was observed: the shift of radioactive glucan from fraction 4 in the 1st incubation to fraction 8 after the second incubation and the corresponding decrease in fraction 9 , suggesting a precursor-product relationship. Since in this particular experiment the different glucan fractions were not analysed in detail, with the present data this result has to be considered as a working hypothesis.

\section{Discussion}

The in vitro sequential synthesis of the prenyldiphosphate-linked heptasaccharide repeat unit of acetan, using EDTA-treated cells as enzymic preparation and the respective sugar nucleotide donors, has been described in previous publications (García et al., 1974; Couso et al., 1980, 1982). Nevertheless, with this enzymic preparation the polymerization product, acetan, was very difficult to detect (L. Ielpi \& M. A. Dankert, unpublished observations), although an indirect approach suggested a precursor-product relationship (Iñon de Iannino et al., 1988). The use of electroporated cells as enzyme source has now allowed the synthesis of polymer in substantial amounts (Tables 1 and 2, Fig. 5).

It looks as if this technique, already widely applied to introduce large molecules into bacterial cells (Potter, 1988) causes less damage to the cell envelope than EDTA treatment, known to release a series of compounds from the interior of the cell, polysaccharides, proteins and nucleic acids among them (Leive, 1974). With this new electroporation technique, the polymerizing enzyme(s) remains active. It is interesting to note that the in vitro synthesis of lipid-linked repeat units using EDTA-treated cells, has been reported for several systems (Tolmasky $e t$ 
al., 1982; Staneloni et al., 1984; Bossio et al., 1986) but only in the case of xanthan, has a clear in vitro polymerization process been reported (Ielpi et al., 1981, 1993). A detailed study of the electroporation technique, as well as its application to a series of exopolysaccharidesynthesizing systems, will be described elsewhere (C. E. Semino \& M. A. Dankert, unpublished results).

The identification of the polymer formed with acetan was based not only on its size but also on the incorporation of the different constituents, glucose, mannose, glucuronic acid, rhamnose and acetate (Fig. 5), and in the permethylation analysis of the $\left[{ }^{14} \mathrm{C}\right]$ Glclabelled acetan produced. The branching glucose was clearly detected in the polymer (Fig. 6a), and was replaced by the respective mono-substituted derivative in the heptasaccharide precursor (Fig. 6b). As in the case of xanthan biosynthesis, part of the linear repeat unit becomes a branch in the final product as a consequence of the polymerization process (Ielpi et al., 1981, 1993).

Finally, the two-step incubation experiment showed that at least part of the lipid-linked repeat units are transferred to the polymer fraction confirming the role of intermediates originally assigned (Table 3) (Couso et al., 1982). One point for which there was no clear answer was the presence of free repeat units in the water-soluble supernatant of this experiment (Table 3, fraction 6 , hepta). This result may reflect the 'physiological' liberation of repeat units (Amemura et al., 1983) or simply indicate that the enzyme(s) involved in the export process is not size-specific, and less damaged than that involved in the polymerization reaction.

The analysis of the products of permethylated acetan, as mentioned in Results, showed the formation of small amounts of 2,3,4,6-tetra-O-methyl glucose (Fig. 6a), originated in a terminal glucose. Its presence can be explained assuming that in the polymer, some of the repeat units (about $20 \%$ ) lack the terminal rhamnose. The relative amount of this tetra-methyl derivative is higher in the lipid-linked repeat unit $(30-35 \%$ of hexasaccharide; Fig. 4 and Fig. $6 b$ ), suggesting that the polymerizing mechanism preferentially selects complete heptasacharide precursors. The presence of truncated repeat units in the polymer opens the possibility, through the isolation of appropriate mutants, to obtain new exopolysaccharides, as described for the xanthan system (Betlach et al., 1987; A. A. Vojnov \& M. A. Dankert, unpublished observations). In fact, whilst this paper was in preparation the isolation of Acetobacter xylinum cellulose-minus mutants, one of them called CR 1/4, producing a 'truncated acetan' polymer with a repeat unit of only four sugars, was reported (MacCormick et al., 1993). It is interesting to note that the yield of this 'truncated acetan' was less than that of the wild-type acetan, suggesting that the polymerizing system works better with the wild-type prenyl heptasaccharide precursor, as observed in this study.

Acetan is acetylated in some, for the moment, unknown position. Substantial amounts of $\left[{ }^{14} \mathrm{C}\right]$ acetate were incorporated both in the acetan and in the hexaheptasaccharide fractions (Table 2, fractions 1 and 2, hexa-heptasaccharide). But, surprisingly, larger amounts of radioactivity were incorporated into the neutral and charged components of the 1203 extracts and of the water washings (Table 2, fraction 2, other; and fraction 3 , other). They were identified as a mixture of lipidlinked and free acetylated di- and trisaccharides (cellobiose and mannosyl cellobiose) and their corresponding cyclic phosphate esters, respectively. Lipid diphosphate sugars readily decompose, especially in mild alkaline media, producing the respective 1,2-cyclic phosphate esters, provided the hydroxyl group at $\mathbf{C}-2$ is free and in cis configuration with the phosphate bridge (Couso et al., 1982). It looks clear that $\left[{ }^{14} \mathrm{C}\right]$ acetate labels only acetan or acetan precursors, but it is not so clear why the different amounts of the acetylated tri- and disaccharides accumulate. It is tempting to think that once the lipidlinked oligosaccharide is acetylated the following sugar has some difficulties in being incorporated, as if the acetylation process should follow the sugar transfer. In contrast, these results show that the first two or three hexoses next to the reducing end of the repeat unit carry one or more acetyl groups.

The enzyme preparation used not only led to the production of acetan but also to all the other compounds already described working with EDTA-treated cells: prenyl monophosphate $\beta$-galactose (Romero et al., 1977 a), prenyl monophosphate $\beta$-mannose (Couso et al., 1980), and a lipid-bound GlcA (Couso et al., 1986).

The synthesis of a glucan, mentioned in early work (García et al., 1974) has been confirmed. Its presence and structure were also reported by other laboratories (Sandermann \& Dekker, 1979; Amemura et al., 1985). The glucan formed has now been fractionated into at least three groups: $(a)$ a neutral glucan of apparent molecular mass $500000 \mathrm{Da}$, partially extracted with 1203 solvent (Table 2, fraction 2, other) and with water (Table 2, fraction 3, neutral, and Fig. 7a), (b) a proteinassociated glucan (charged and TCA-insoluble), also of apparent molecular mass $500000 \mathrm{Da}$ (Table 2, fraction 3, charged, and Fig. 7a); and (c) a series of smaller molecular mass glucans partially associated with protein (Table 2, fraction 4, glucan alkali soluble, and Fig. $7 b$ ). Results from the two-step experiment suggest that this fraction (Table 3, fraction 9) could be a precursor of fraction 8. The biosynthesis of $\beta$-1,2-cyclosophorans has been carefully studied in Rhizobium and Agrobacterium systems (Zorreguieta et al., 1990). It looks as if this linear glucan (Amemura et al., 1985) follows a similar bio- 


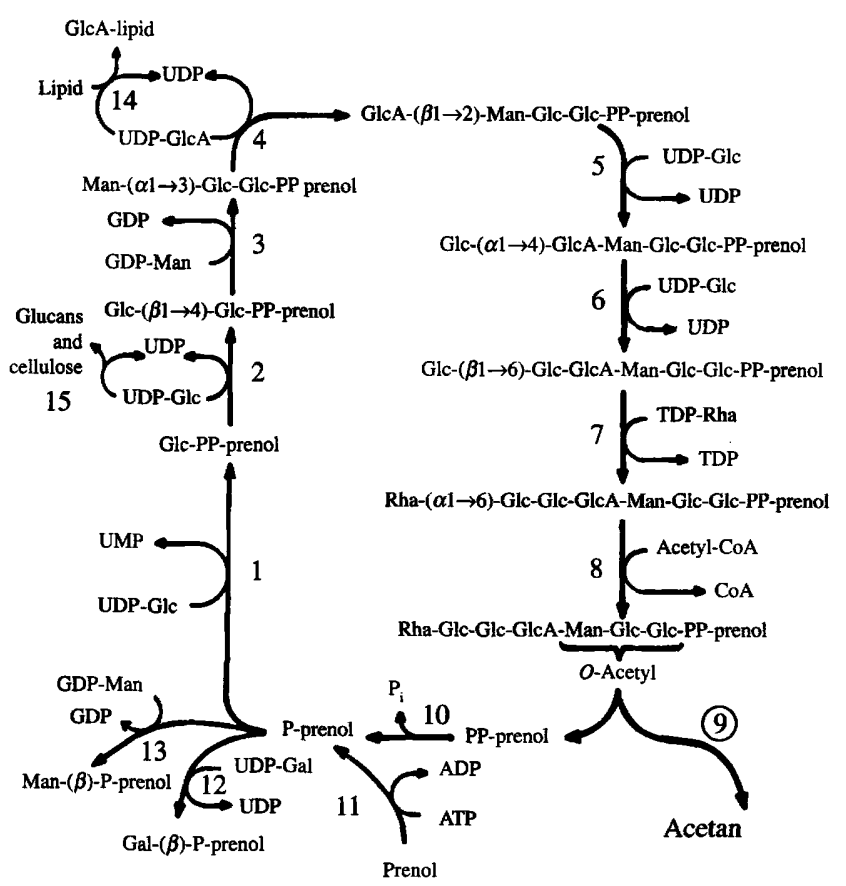

Fig. 8. Proposed scheme for the reactions involved in the biosynthesis of acetan and of the other saccharides mentioned in this work.

synthetic pathway. Since all these fractions were not degraded by $\alpha$-amylase, the possibility of dealing with glycogen derivatives was ruled out.

In summary, the utilization of electroporated bacterial cells as enzyme system opens a broad field in polysaccharide biosynthesis, that may be extended to other problems.

Several controls were performed with this technique to rule out the possibility of dealing with in vivo results. For instance, when $\left[{ }^{14} \mathrm{C}\right] \mathrm{Glc}$ was substituted for the labelled sugar nucleotide donors, the incorporation to 1203 extracts was very low (less than $2 \%$ of that obtained with UDP- $\left.\left[{ }^{14} \mathrm{C}\right] \mathrm{Glc}\right)$ and no acetan formation was detected. Similarly, the permeated cells kept this property for at least $1 \mathrm{~h}$.

The proposed pathway of acetan biosynthesis, and of the other saccharide derivatives, is represented in Fig. 8. Reactions 1 to 7 depict the sequential assembly of the repeat unit (Couso et al., 1982). Reaction 8 simply describes the acetyl transfer to the complete repeat unit in a general manner, since the number of acetyl groups, as well as the sites of acetylation, are unknown.

Reaction 9 represents, also in a general manner, the polymerization process. For instance, it is not clear if the newly formed repeat units are incorporated at the nonreducing or reducing end of the growing acetan chain. Recent results indicate that xanthan chains grow at the reducing end (Ielpi et al., 1993) as demonstrated for the $O$-antigen chains of Salmonella lipopolysaccharide (Robbins et al., 1967).
Reactions 10 and 11 refer to the formation of the prenyl phosphate acceptor, either by removal of a phosphate through a specific phosphatase (Romero, 1977) or by phosphorylation of the free phenol by means of a specific kinase (Romero et al., 1977b).

Reactions 12,13 and 14 refer to the formation of the galactose, mannose and glucuronic acid derivatives already mentioned, and reaction 15 simply indicates that both cellulose (Ross et al., 1991) and glucans follow independent pathways of biosynthesis. A more detailed study of the latter process is under way.

The authors wish to thank Ms Susana Raffo and María de los Angeles Curto for the excellent technical assistance in the preparation of labelled sugar nucleotides. M.A.D. is a Career Investigator of the Consejo Nacional de Investigaciones Científicas y Técnicas (CONICET) (Argentina). This work was supported in part by grants from the Swedish Agency for Research Cooperation with Developing Countries (SAREC) and from Shell CAPSA.

\section{References}

Amemura, A., Hisamatsu, M., Mitan, H. \& Harada, T. (1983). Cyclic $(1,2)-\beta$-D-glucan and the octasaccharide repeating units of extracellular acidic polysaccharides produced by Rhizobium. Carbohydrate Research 114, 277-285.

Amemura, A., Hashmoto, T., Kolzumi, K. \& Utamura, T. (1985). Occurrence of extracellular (1-2)- $\beta$-D-glucans and (1-2)- $\beta$-D-glucooligosaccharides in Acetobacter. Journal of General Microbiology 131, 301-307.

Betlach, M. R., Capage, M. A., Doherty, D. H., Hassler, R. A., Henderson, N. M., VANDERSLICE, R. W., MARRELli, J. D. \& Ward, M. B. (1987). Genetically engineered polymers: manipulation of xanthan biosynthesis. In Progress in Biotechnology, vol. 3, Industrial Polysaccharides pp. $30-50$. Edited by M. Valpani. Amsterdam: Elsevier.

Bossio, J. C., IÑón de IANNINo, N. \& DANKERT, M. A. (1986). In vitro synthesis of a lipid-linked acetylated and pyruvilated oligosaccharide in Rhizobium trifolii. Biochemical and Biophysical Research Communications 134, 205-211.

BRAY, G. A. (1960). A simple efficient liquid scintillator for counting aqueous solutions in a liquid scintillation counter. Analytical Biochemistry 1, 279-285.

Couso, R. O., Ielpi, L., García, R. C. \& DankerT, M. A. (1980). Synthesis of mannosyl cellobiose diphosphate prenol in Acetobacter xylinum. Archives of Biochemistry and Biophysics 204, 434-443.

Couso, R. O., Ielpi, L., García, R. C. \& DanKerT, M. A. (1982). Biosynthesis of polysaccharides in Acetobacter xylinum. Sequential synthesis of a heptasaccharide diphosphate prenol. European Journal of Biochemistry 123, 617-627.

Couso, R. O., Iñon de IANnino, N. \& Dankert, M. A. (1986). Characterization of a lipid-linked glucuronic acid derivative in Acetobacter xylinum preparations. Anales de la Asociación Química Argentina 74, 783-793.

Couso, R. O., IelPI, L. \& DankerT, M. A. (1987). A xanthan-gum-like polysaccharide from Acetobacter xylinum. Journal of General Microbiology 133, 2123-2135.

Dankert, M. A., Wright, A., Kelly, W. S. \& Robbins, P. W. (1966). Isolation, purification and properties of the lipid-linked intermediates of $O$-antigen biosynthesis. Archives of Biochemistry and Biophysics 116, 425-435.

Delmer, D. P. (1983). Biosynthesis of cellulose. Advances in Carbohydrate Chemistry and Biochemistry 41, 105-153.

Elbein, A. D., Barker, G. A. \& Hassid, W. Z. (1966). Cellulose synthesis from plants. Methods in Enzymology 8, 416-418.

García, R. C., RECONDO, E. \& DANKERT, M. A. (1974). Polysaccharide biosynthesis in Acetobacter xylinum. Enzymatic synthesis of lipid 
diphosphate and monophosphate sugars. European Journal of Biochemistry 43, 93-105.

HeStrin, S. \& Schramm, M. (1954). Preparation of freeze-dried cells capable of polymerizing glucose to cellulose. Biochemical Journal 58, 345-352.

IelPI, L., Couso, R. O. \& DANkert, M. A. (1981a). Lipid-linked intermediates in the biosynthesis of xanthan-gum. FEBS Letters 130 , 253-256.

IelPI, L., Couso, R. O. \& DankerT, M. A. (1981 b). Pyruvic acid acetal residues are transferred from phosphoenol pyruvate to the pentasaccharide P-P-lipid. Biochemical and Biophysical Research Communications 102, 1400-1408.

IelPI, L., Couso, R. O. \& DaNkerT, M. A. (1983). Xanthan gum biosynthesis: acetylation occurs at the prenyl-phospho-sugar stage. Biochemistry International 6, 323-333.

IELPI, L., Couso, R. O. \& DANKERT, M. A. (1993). Sequential assembly and polymerization of the polyprenol-linked pentasaccharide repeating unit of the xanthan polysaccharide in Xanthomonas campestris. Journal of Bacteriology 175, 2490-2500.

IÑon de IANNino, N., Couso, R. O. \& DANKeRT, M. A. (1988). Lipidlinked intermediates and the synthesis of acetan in Acetobacter xylinum. Journal of General Microbiology 134, 1731-1736.

Jansson, P. E., KenNe, L. \& Lindberg, B. (1975). Structure of the extracellular polysaccharide from Xanthomonas campestris. Carbohydrate Research 45, 275-282.

JANSSON. P. E., LiNDBERG, J., SWARNA Wimilasiri, K. M. \& DANKeRT, M. A. (1993). Structural studies of acetan, an exopolysaccharide elaborated by Acetobacter xylinum. Carbohydrate Research (in the Press).

LEIVE, L. (1974). The barrier function of the Gram-negative envelope. Annals of the New York Academy of Sciences 235, 109-127.

LI, E., TABAS, I. \& KoRNFELD, S. (1978). The synthesis of complex-type oligosaccharides. Structure of the lipid-linked oligosaccharide precursor of the complex-type oligosaccharides of the vesicular stomatitis virus G protein. Journal of Biological Chemistry 253, 7762-7770

MacCormick, C. A., Harris, J. E., Gunning, A. P. \& Morris, V. J. (1993). Characterization of a variant of the polysaccharide acetan produced by a mutant of Acetobacter xylinum strain CR1/4. Journal of Applied Bacteriology 74, 196-199.
POTTER, H. (1988). Electroporation in biology: methods, applications and instrumentation. Analytical Biochemistry 174, 361-373.

Robins, P. W., Bray, D., Dankert, M. A. \& Wright, A. (1967). Direction of chain growth in polysaccharide synthesis. Science 158, $1536-1542$.

ROMERO, P. A. (1977). Función de los poliprenoles en la síntesis de polisacáridos. PhD Thesis, University of Buenos Aires.

Romero, P. A., García, R. C. \& DanKert, M. A. (1977a). Synthesis of polyprenol-monophosphate- $\beta$-galactose by Acetobacter xylinum. Molecular and Cellular Biochemistry 16, 205-212.

Romero, P. A., Garcia, R. C. \& Dankert, M. A. (1977b). Polyprenol kinase in Acetobacter xylinum. Acta Physiologica Latinoamericana 26, 434-437.

Ross, P., Mayer, R. \& Benziman, M. (1991). Cellulose biosynthesis and function in bacteria. Microbiological Reviews 55, 35-58.

SANDERMANN, H., JR \& DEKKER, R. F. H. (1979). $\beta$-1,2-Glycosyl transfer by membrane preparations from Acetobacter xylinum. FEBS Letters 107, 237-240.

SANDFord, P. A. \& ConRad, M. E. (1966). The structure of the Aerobacter aerogenes A3 (Sl) polysaccharide. I. A re-examination using improved procedures for methylation analysis. Biochemistry $\mathbf{5}$, $1508-1517$.

SMith, F. \& Montgomery, R. (1956). End group analysis of polysaccharides. In Methods of Biochemical Analysis, vol. 3, pp. 154-157. Edited by D. Glick, New York and London: Interscience.

Staneloni, R. J., Tolmasky, M. A. \& Leloir, L. F. (1984). Lipid bound saccharides containing glucose and galactose in Agrobacterium tumefaciens. Journal of General Microbiology 130, 869-879.

Tolmasky, M. E., Stanelon, R. J. \& Leloir, L. F. (1982). Lipidbound saccharides in Rhizobium meliloti. Journal of Biological Chemistry 257, 6751-6757.

Trevelyan, W. E., Procter, D. P. \& Harrison, J. S. (1950). Detection of sugars on paper chromatograms. Nature, London 166, 444-445.

ZeVenhuizen, L. P. T. M. \& VAN NeER Ven, A. R. W. (1983). ( $1 \rightarrow 2)-\beta$ D-glucan and acidic oligosaccharides produced by Rhizobium meliloti. Carbohydrate Research 118, 127-134.

Zorreguieta, A., Cavaignac, S., Geremía, R. A. \& Ugalde, R. A. (1990). Osmotic regulation of $\beta(1,2)$ glucan synthesis in members of the family Rhizobiaceae. Journal of Bacteriology 174, 4701-4709. 